\title{
Supporting the Design of a Management Accounting System of a Company Operating in the Gas Industry with Business Process Modeling
}

\author{
Nikolaos A. Panayiotou and Ilias P. Tatsiopoulos \\ National Technical University of Athens, School of Mechanical Engineering, Section of \\ Industrial Management \& Operational Research, 15780 Zografos Campus, Athens, Greece \\ \{panayiot, itat\}@central.ntua.gr
}

\begin{abstract}
Traditional cost accounting systems are rarely capable to fully support management decision making in organizations. The design of innovative costing systems like Activity Based Costing (ABC) can offer a valuable alternative, however, their design proves to be very challenging. Although the use of business process modeling in cooperation with Activity Based Costing and Activity Based Management (ABM) has been extensively covered in the literature, few articles can be found that refer to the design of a full costing system with the use of a modeling architecture. This paper presents the use of a proposed business process modeling architecture for the design of a full hybrid traditional accounting and Activity Based Costing system of a company operating in the gas industry. The results of the study suggest that business process modeling can enhance the design of a costing system, minimize errors and maximize the acceptance level of all the stakeholders of the system.
\end{abstract}

Keywords: Business Process Modeling (BPM), Management Accounting System, Activity-Based Costing (ABC), Cost Center Accounting, ARIS.

\section{Introduction}

A typical traditional cost system accumulates costs by classifying them into certain categories such as labour, materials and overhead costs and then assigns these costs to cost objects [1]. Although the above approach is adequate for financial accounting purposes, it cannot always fully satisfy the needs of top management that is concerned with identifying, presenting and interpreting information for formulation strategy, planning and controlling activities, decision taking, optimizing the use of resources, disclosure to stakeholders and safeguarding assets [2]. Traditional accounting also involves the establishment of an accounting-oriented organizational view which is reflected in the organization evaluation structure [3]. This is a typical situation where accounting data only hardly reflects process-oriented organizational structures. For organizations striving to become more process-oriented, it would be both desirable and necessary to also reflect process structures within an organization's accounting model [3]. 
Business Process Modeling (BPM) has been extensively used by companies to improve their business process understanding [4]. A qualitative model that provides a graphical interpretation of the process captures the structure of a business process. The objective of qualitative process modeling is to visualize the process and to achieve a commonly agreed view of the process structure. Graphical process presentation facilitates communication between people and helps in developing a common conceptual model of what goes on in the studied process [5]. Many researchers have described objectives associated with the adoption of Business Process Management and Business Process Modeling within organizations [6-8].One popular application covered by many articles is the use of modeling in Activity Based Costing (ABC) and Activity Based Management (ABM) systems [5], [9-12]. However, few [12] emphasize on the design of a full costing system with the use of a business process modeling architecture.

The hypothesis of this paper is that Business Process Modeling can substantially assist the design of a costing system in an organization providing a number of benefits such as rational and systematic identification of cost activities, minimization of errors, improvement on the compatibility of traditional and innovative accounting concepts and maximization of acceptance from all the stakeholders of the costing system The Architecture of Integrated Information Systems (ARIS) has been used as the basis for the development of the proposed architecture, since it originates from academic research, it is well documented within the literature, and in particular it has proven its applicability and usefulness for practice. ARIS provides a framework to help dealing with the complexity of designing and implementing business processes and process aware information systems [13]. ARIS recognizes different views that provide a holistic perspective on business processes by describing "who" does "what", "how", "when" and "why". Moreover, the aspect of cost is taken into account in the framework permitting the interrelation of accounting concepts with business processes and activities. The proposed architecture is demonstrated through a case study of a company operating in the gas industry.

\section{A Case Study}

The company under discussion operates in the gas industry and is the leader in the national market where it operates. Among its strategic objectives is the continuous natural gas supply at competitive prices, maintaining its leading position in the domestic market, while enhancing its presence inside and outside of the national territory by developing new applications and natural gas services. The company is the immediate natural gas supplier of electricity producers, large customers with annual consumption of over 10 million $\mathrm{m} 3$, gas supply companies, end users in regions where gas supply companies have not yet been established and gas-powered vehicles.

The importance of costing for the company is high, as it affects important decisions concerning the procurement mix, capacity reservation in the national natural gas transmission system, scheduling, pricing of different customer categories and future investment initiatives. 


\subsection{Problem Definition}

The existing accounting system of the company was covering the minimum needs for financial reporting but it was not adequate for the support of decision making. As a result the Sales and the Planning Divisions felt the need to maintain custom-made information systems in order to keep data needed for decisions made at a short-term and medium-term level. The existence of more than one costing systems (one formal and some others informal) caused problems in management reporting and led to inconsistent information provision to the different company divisions. In order to cover its unsatisfied needs, the company decided to design a complementary management accounting system, without affecting its existing financial-oriented accounting system. The objectives set by the new system can be summarized as follows:

- Management view of cost with accurate and adequate data in a unique way for all the divisions of the company.

- Full compatibility of the cost provided for financial accounting and management accounting.

- Rational allocation of cost to the final cost objects (customers) with the use of the appropriate cost drivers and beyond the traditional volume and turnover drivers.

- Use of the concept of cost activities in order to provide meaningful information to management.

- Improved and more detailed analysis of the sales and distribution functions.

- Cost allocation to each sector and sub-sector of the existing customers.

The design of the new system should confront with some challenging issues such as the recognition of all costing activities, the selection of the appropriate level of detail, the "bridging" of diverting views of cost provided by different departments, the identification of the existing hierarchies in the different costing dimensions and the guarantee of compatibility between the new and the old system. Taking these into account and in order to support the successful design of the new management accounting system, the adoption of an appropriate business process modeling architecture was decided.

\subsection{Methodological Approach}

The hybrid traditional costing and Activity Based Costing system was based on a four level hierarchy which is depicted in Figure 1. According to this, cost accumulation takes place in four levels: cost center, activity, sector/ sub-sector and cost object (customer). All four levels accumulate the same amount of cost. For example, the cost of a cost center equals the cost of activities it includes. Cost data entry must at least include the information of the corresponding activity or cost center. If cost data entry does not take place on a cost object level, cost allocation to the lower levels of the hierarchy is based on predefined cost drivers. 


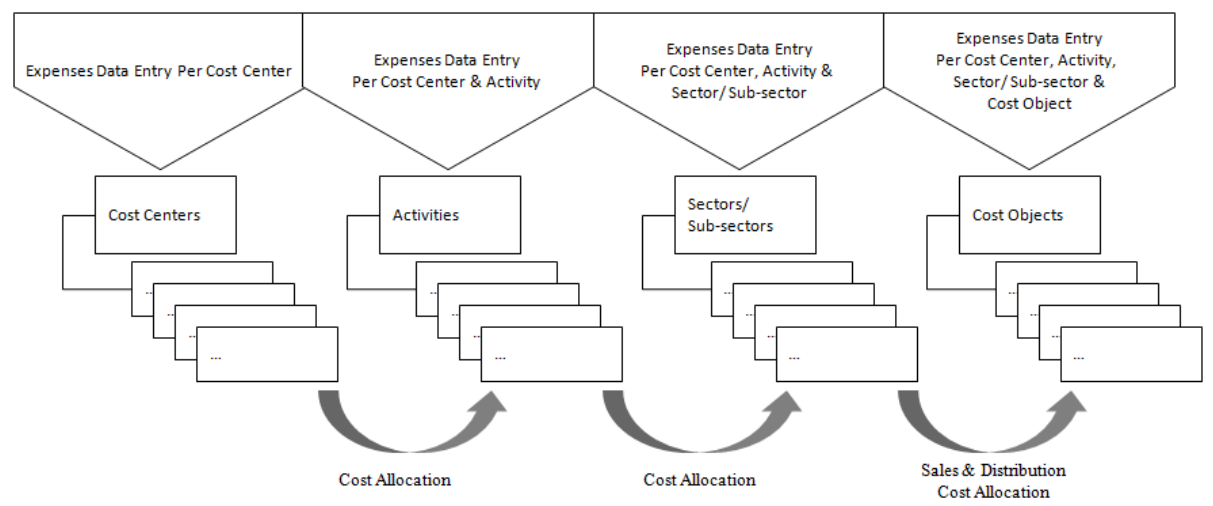

Fig. 1. Suggested Costing Approach

In order to support the design of the new costing system, a business process management architecture was constructed based on selected methods of the ARIS framework. In this framework each modeling object is defined through different perspectives (organization, function, data, process and output view). Six ARIS methods were selected for the construction of the modeling architecture covering the four of the five views of the framework. The selected methods, which are depicted in Figure 2 , were interrelated and connected through the process view.

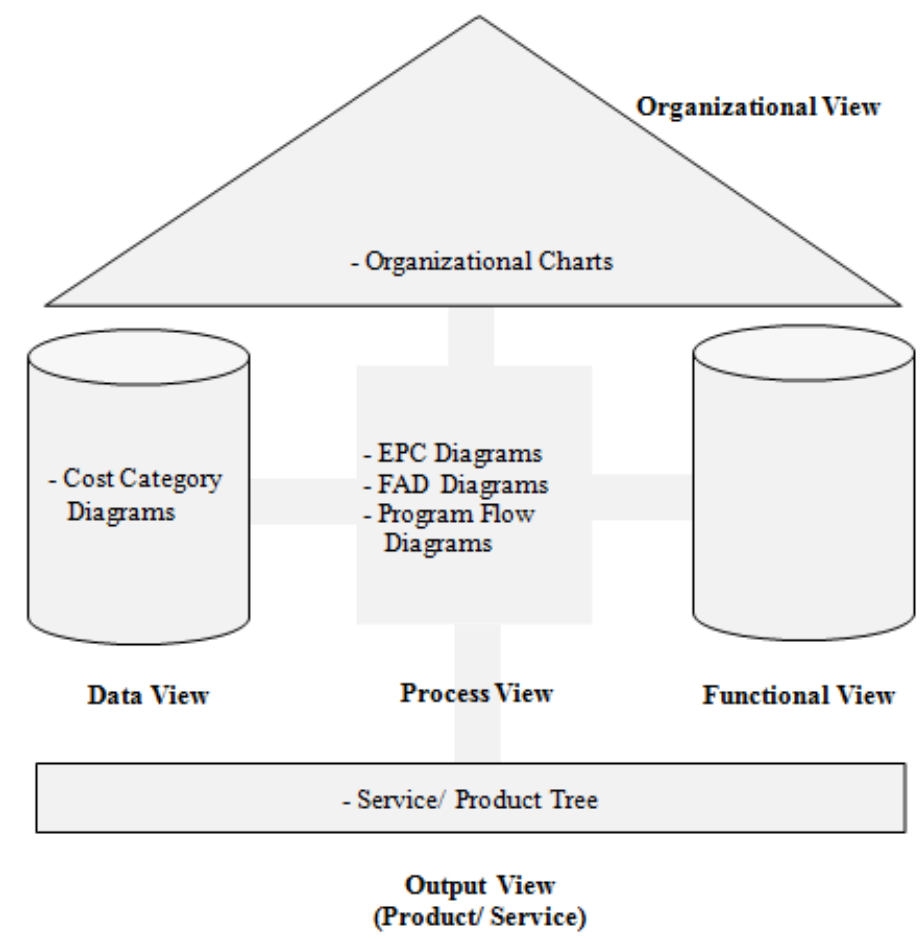

Fig. 2. Business Process Modeling Architecture 


\subsection{Design of the Management Accounting System}

The first step in the design of the costing system was the definition of cost centers. Cost center analysis is in fact an organizational issue, as in the majority of organizations, cost centers coincide with organizational units. In the case study under discussion the cost centers coincided with divisions and ARIS Organizational Chart was used for their modeling.

The final cost objects of the company were customers and not products as in most of the cases. Customers are part of a hierarchy (its last level) which starts from the sector and sub-sector and continuous with customer categories. This hierarchy was modeled with the use of Service/ Product Diagram.

The definition of cost elements is a classification used by traditional accounting systems in order to describe the nature of a cost entry. Typical cost elements are salaries, wages, material cost, taxes, financial expenses, amortization and other costs. In order to model cost elements, the ARIS Cost Category Diagram was used.

The central concept of the designed costing system was the costing activity. The costing activities were defined in such a way that they were in fact a hierarchical decomposition of the existing cost centers in order to guarantee compatibility between the traditional accounting system and the management accounting (activity oriented) system. In order to model the activity model, the simplified Event-driven Process Chain (EPC) diagram was used. For each identified activity, a corresponding Function Allocation Diagram (FAD) was assigned in order to connect each activity with other objects necessary for the design of the costing system, such as the cost center, sector/ sub-sector where this costing activity is relevant, business function (production, sales, distribution, research and development, finance), cost element and cost driver.

All the designed algorithms for the allocation of cost in the defined four levels (depicted in Figure 1) were modeled with the use of ARIS Program Flow Charts (PF).

The interrelation of the modeling objects used in the six methods described in the above paragraphs permitted the generation of a report fully describing the designed costing system (including the information of cost center, business function, sector, cost element and cost driver for each activity).

\section{Conclusions}

The use of a developed business process modeling architecture in the case study presented in the paper demonstrated some of the benefits that can be achieved in the design of management accounting systems. Management accounting has the important task to communicate both financial and non-financial information to the stakeholders of an organization, relating to its activities, in order to enable them take better decisions and improve the efficiency and effectiveness of existing operations. The relation of management accounting with the performed activities in order to give full meaning to numbers is an important reason that increases the need of business process modeling. The proposed architecture based on the ARIS framework is definitely not the only way to cover business modeling needs. However, it proved to be very effective in the connection of different views of an accounting system satisfying all the 
stakeholders of such a system. Its effectiveness was proved, firstly by the fact that stakeholders' costing needs were satisfied (something that could not be achieved before the use of the suggested approach). Taking into account that the penetration of formal and primary activity based costing systems in Europe is very low due to existing difficulties in their acceptance, this is a good indication that the approach used for the design of the new system was effective. Secondly, it can be argued that the approach was effective because it offered useful costing functionality such as cohesively integrated views, activity orientation without losing the traditional desirable functionality and decision making support through the meaningful and flexible calculation of cost guaranteed by the integrated methods of the approach.

The most important of the benefits realized in the case study can be summarized as follows:

- Connection of the accounting view with the sales and operation view in a consistent way.

- Provision of meaningful information for decision making related to processes and activities as well as to organisational units and functional structures.

- Support of the design phase of the management accounting system enabling emphasis on the aspects that mattered.

- Generation of accurate functional specifications for the implementation of the costing system in a software.

- Provision of a structured approach for the control of the designed system and the critical review of the developed business rules for cost allocation.

- Improvement in the degree of acceptance of the new accounting system by all the stakeholders.

- Facilitation of future maintenance and improvement of the costing system in such a way that reflects real business changing practices.

The application of the suggested BPM approach for the design of other management accounting systems in the future (in the same or other sectors) is necessary in order to justify the positive results achieved in the case study presented in this paper. The design of a pure activity based costing system with the use of the suggested approach will be even more didactical and will better help in the expansion of the modeling architecture with the potential use of a larger number of views and modeling objects. Finally, the expansion of the modeling architecture in order to support the implementation phase will enhance its practical use.

\section{References}

1. Drury, C.: Management Accounting for Business Decisions, 2nd edn. Thomson Learning (2001)

2. Rama Gopal, C.: Accounting for Managers (Starting From Basics). New Age International (P) Ltd., Publishers (2009)

3. Scheer, A.-W.: Business Process Engineering, 3rd edn. Springer, Berlin (1994) 
4. Laakso, T.: Performance Evaluation and Process Interventions: A Method for Business Process Development. Finnish Academy of Technology, Espoo (1997)

5. Tornberg, K., Jammsen, M., Paranko, J.: Activity-Based Costing and Process Modeling for Cost-conscious Product Design: A Case Study in a Manufacturing Company. International Journal of Production Economics 79, 75-82 (2002)

6. Davenport, T.H.: Process Innovation. Reengineering Work through Information Technology. Harvard Business School Press, Boston (1993)

7. Hammer, M., Champy, J.: Reengineering the Corporation: A Manifesto for Business Revolution. Harper Business, New York (1993)

8. Harmon, P.: Business Process Change. A Guide for Business Managers and BPM and Six Sigma Professionals, 2nd edn. Morgan Kaufmann, Burlington (2007)

9. Tatsiopoulos, I.P., Panayiotou, N.A.: The Integration of Activity Based Costing and Enterprise Modeling for Reengineering Purposes. International Journal of Production Economics 66(1), 33-44 (2000)

10. Schulze, M., Seuring, S., Ewering, C.: Applying Activity-based Costing in a Supply Chain Environment. International Journal of Production Economics 135, 716-725 (2012)

11. Baykasog, A., Kaplanog, V.: Application of Activity-based Costing to a Land Transportation Company: A Case Study. International Journal of Production Economics 116, 308324 (2008)

12. Sonnenberg, C., Huemer, C., Hofreiter, B.: Linking Accounting and Process-aware Information Systems - Towards a Generalized Information Model for Process-oriented Accounting. In: European Conference on Information Systems (ECIS 2011), Helsinki, Finland (2011)

13. Scheer, A.-W.: ARIS - Business Process Modeling. Springer, Berlin (1999) 